\title{
O ONTEM E O HOJE DA INDÚSTRIA CULTURAL: DO FOLHETIM AOS VLOGS E REDES SOCIAIS
}

\author{
The yesterday and today of cultural industry: from feuilleton to vlogs and social \\ network
}

Fabio Goulart*

Resumo: Este artigo está dividido em três partes e tem como objetivo geral apresentar o desdobramento histórico da indústria cultural desde seu princípio até os dias atuais, analisando e apresentado a crítica dos filósofos Theodor Adorno e Max Horkheimer à tal indústria. Baseando-se em autores contemporâneos de diversas áreas é feita uma atualização de tal crítica, contemplando os conceitos de globalização e comunicação em rede, bem como as tecnologias da tv por satélite, internet e web 2.0 que não existiam em meados dos anos 1940.

Palavras-chaves: Industria Cultural. Teoria Crítica. Globalização. Internet. Web 2.0.

\begin{abstract}
This paper is divided into three parts and has the overall objective is present the historical development of cultural industry since its inception to the present day, analyzing the critic made by philosophers Theodor Adorno and Max Horkheimer to this industry will also be crafted, as based on contemporary authors from different areas, one update of this critic will made covering the concepts of globalization and communication network, as well as technologies of satellite tv, internet and web 2.0 that did not exist in the mid-1940s.
\end{abstract}

Keywords: Cultural Industries. Critical Theory. Globalization. Internet. Web 2.0.

\footnotetext{
* Mestre em Filosofia pela Pontifícia Universidade Católica do Rio Grande do Sul (PUCRS) e pela Universidad de la Republica (URUGUAI - Sandwich). Bolsista: Conselho Nacional de Desenvolvimento Científico e Tecnológico. Contato: fabiogt @zipmail.com.br
}

\begin{tabular}{|c|c|l|l|c|c|}
\hline intuitio & $\begin{array}{c}\text { ISSN } \\
1983-4012\end{array}$ & Porto Alegre & Vol.7- $\mathrm{N}^{\circ} .2$ & $\begin{array}{c}\text { Novembro } \\
2014\end{array}$ & p.104-121 \\
\hline
\end{tabular}




\section{Indústria cultural}

Em linhas gerais a indústria cultural (Kulturindustrie) é um termo crítico criado e apresentado pelos filósofos alemães Theodor Adorno e Max Horkheimer pela primeira vez no capítulo intitulado $O$ iluminismo como mistificação das massas na obra Dialética do Esclarecimento, com a finalidade de ilustrar a situação de submissão da arte e dos veículos de comunicação frente à economia capitalista e à cultura burguesa em geral. Como o próprio termo já diz, trata-se de um ramo da indústria que produz e distribui produtos culturais, porém o problema que esta prática tão corriqueira produz é extremamente pesado e complexo.

Não existe uma data exata para o surgimento da indústria cultural, porém o pensador brasileiro Teixeira Coelho nos faz alguns esclarecimentos sobre esta questão. Primeiramente não se pode falar em indústria cultural antes da Revolução Industrial do século XVIII. Evidentemente foi necessário a pré-existência de uma cultura industrial para que a cultura propriamente dita pudesse passar a ser industrializada. Porém, o fator definitivo que delimitaria a criação de tal atividade economia aparece só alguns anos depois:

[...] surge somente após a formação de "uma economia de mercado, isto é, de uma economia baseada no consumo de bens; é necessário, enfim, a ocorrência de uma sociedade de consumo, só verificada no século XIX em sua segunda metade. ${ }^{1}$

Dessa forma diríamos que a indústria cultural e sua cultura para massa são frutos do fenômeno da industrialização, mas não somente isso, são fruto da submissão do homem às novas condições de trabalho e consumo burguesas citadas no primeiro capítulo. Ou seja, são fruto da nova forma de economia ditada pelo ritmo das máquinas, pela exploração do homem sobre o próprio homem, pela reificação e pela alienação.

Dois desses traços merecem uma atenção especial: a reificação (ou transformação em coisa: a coisificação) e a alienação. Para essa sociedade, o padrão maior de avaliação tende a ser a coisa, o bem, o produto; tudo é julgado como coisa, portanto tudo se transforma em coisa - inclusive o homem. E esse homem reificado só pode ser um homem alienado: alienado de seu trabalho, que é trocado por um valor em moeda inferior às forças por ele gastas; alienado do produto de seu trabalho, que ele mesmo não pode comprar, pois seu trabalho não é remunerado a altura do que ele mesmo produz; alienado, enfim, em relação a tudo, alienado de seus projetos, da vida do país, de sua própria vida, uma vez que não dispõe de tempo livre, nem de instrumentos teóricos capazes de permitir-lhe a crítica de si mesmo e da sociedade. ${ }^{2}$

Todo e qualquer bem cultural, informação ou arte antes de se tornar produto reproduzido massivamente pela indústria cultural passam pelo minucioso processo de

\footnotetext{
${ }^{1}$ COELHO, 1993, p.6.

${ }^{2}$ COELHO, 1993, p.6.
}

\begin{tabular}{|c|c|l|l|c|c|}
\hline intuitio & $\begin{array}{c}\text { ISSN } \\
1983-4012\end{array}$ & Porto Alegre & Vol.7- $\mathrm{N}^{\mathrm{o}} .2$ & $\begin{array}{c}\text { Novembro } \\
2014\end{array}$ & p.104-121 \\
\hline
\end{tabular}


gatekeeping a fim de só se produzir e reproduzir aquilo que aceite o fim último de movimentar a maquinaria econômica: seja vendendo produtos, ou seja sendo vendido como produto (e até mesmo ideias e ideais podem ser considerados produtos neste paradigma de reificação). Neste cenário toda cultura, informação e arte deixam de ser fruto de livre expressão e perdem seu poder crítico. Diríamos que tornam-se um produto, fabricado, vendido, consumível e descartável. Assim sendo todos produtos da indústria cultural são produzidos para vender para a maior quantidade de indivíduos possível perdendo seus valores críticos, artísticos e transformadores; ou como dito por Adorno e Horkheimer:

O cinema e o rádio não precisam mais se apresentar como arte. A verdade de que não passam de um negócio, eles a utilizam como uma ideologia destinada a legitimar o lixo que propositalmente produzem. Eles se definem a si mesmos como indústrias, e as cifras publicadas dos rendimentos de seus diretores gerais suprimem toda dúvida quanto à necessidade social de seus produtos.

Com o passar dos anos a indústria cultural só se consolidou cada vez mais, com o desenvolvimento das técnicas de transmissão e reprodutibilidade ganhou dimensões gigantescas ainda na Era da Eletricidade no final do século XIX e com a Era da Eletrônica a partir das décadas de 1930-1940 (período da análise de Adorno e Horkheimer) seu poder de penetração e invasão na vida das pessoas se tornou basicamente irrefreável. A consolidação definitiva da indústria cultural se dá a partir da segunda metade do século XX com o capitalismo monopolista. Nesta época o consumo excessivo e massivo se tornou a principal engrenagem econômica e a indústria cultural ficou encarregada de inflar as necessidades de consumo reais através da publicidade direta e indireta transmitidas com seus produtos. ${ }^{4}$ Para Annie Leonard, após a Segunda Guerra Mundial economistas e analistas estudavam formas de impulsionar a economia, o estímulo ao consumo era um dos métodos mais discutidos naquele momento e a solução que surgiria como a norma para o funcionamento do capitalismo monopolista teria vindo do economista Victor Lebow em seu artigo Price Competition in 1955:

Nossa enorme demanda produtiva da economia exige fazemos do consumo nosso modo de vida, que convertamos a compra e uso de bens em rituais, que busquemos nossa satisfação espiritual, nossas satisfações do ego, no consumo. A medida de status social, de aceitação social, de prestígio, está agora a ser encontrada em nossos padrões consumistas de consumo. $\mathrm{O}$ próprio significado e importância de nossas vidas hoje se expressam em termos de consumo. Quanto maiores forem as pressões sobre o indivíduo para estar em conformidade com os padrões sociais seguros e aceitos, mais ele tende a expressar suas aspirações e sua individualidade em termos do que ele veste, dirige, come - sua casa, seu carro, seu padrão de alimento e seus hobbies[...] Nós precisamos que as coisas sejam consumidas, queimadas,

\footnotetext{
3 ADORNO, Theodor W.; HORKHEIMER, Max. Dialética do Esclarecimento. 1947. Disponível em: <http://goo.gl/YDDT7S> Acesso em: 23 de Fevereiro de 2014, p.57.

${ }^{4}$ COELHO, Teixeira. O que é Indústria Cultural. Brasília: Editora Brasiliense, 1993. 46p. Disponível em <http://goo.gl/oeGzmr> Acesso em: 24 de Fevereiro de 2014, p.7.
}

\begin{tabular}{|c|c|l|l|c|c|}
\hline intuitio & $\begin{array}{c}\text { ISSN } \\
1983-4012\end{array}$ & Porto Alegre & Vol.7 $-\mathrm{N}^{\mathrm{o}} .2$ & $\begin{array}{c}\text { Novembro } \\
2014\end{array}$ & p.104-121 \\
\hline
\end{tabular}


substituídas e descartadas em um ritmo cada vez mais acelerado. ${ }^{5}$

Como veremos no decorrer deste trabalho, a indústria cultural não apenas adotou esta norma para a produção de seus produtos como músicas, filmes, romances, etc. como também se tornou o principal veículo transmissor de tal ideologia através de ações como a obsolescência perceptiva. Embora a solução apresentada por Lebow seja voltada para as nações ricas e desenvolvidas, a psicóloga Maria Rita Kehl ressalta que este não foi um projeto que desprezou a pobreza, com a ação efetiva da indústria cultural se tornou um projeto que contemplou maquiando a realidade ao apontar para os pobres uma falsa perspectiva de ascensão econômica através do trabalho que quase nunca ocorre e funciona como mais um elemento de alienação e replicação da economia burguesa que acaba por propagar nas nações não desenvolvidas a imagem do Self-made man que na prática jamais se efetiva para a maioria dos oprimidos ${ }^{6}$. Para Teixeira Coelho este novo way of life propagado pela indústria cultural evidentemente se desenvolveu e consolidou-se primeiramente nos países desenvolvidos, mas através da venda de bens ao nível do imaginário (consumo com os olhos) e da replicação ideológica também exerceu rapidamente seu domínio nos países em desenvolvimento e nos subdesenvolvidos. Segundo ele mesmo nestes países em que a sociedade de consumo sub existe:

O consumo existe antes como valor ainda a alcançar, como meta ainda irrealizada; mesmo assim, ele orienta a organização da sociedade, tendendo a fazê-lo segundo os moldes das sociedades do Primeiro Mundo - razão pela qual todos esses traços típicos da indústria cultural (e seu produto, a cultura de massa) nos países desenvolvidos acabam por aparecer em linhas gerais, na análise do mesmo fenômeno nas demais regiões. ${ }^{7}$

\section{A atualidade da indústria cultural (indústria cultural global)}

Se saltássemos da concepção de indústria cultural feita por Adorno e Horkheimer em meados da década de 1940 e simplesmente aterrissássemos sobre a internet desta segunda década do terceiro milênio, certamente teríamos a sensação de haver um tremendo abismo entre os dois paradigmas. Mas se fizéssemos isto, provavelmente teríamos uma visão desconexa e precipitada frente à web - que por ser um fenômeno contemporâneo ainda não temos a capacidade de emitirmos juízos completos e definitivos sobre a mesma.

Antes de analisarmos a "cultura conectada" precisamos entender alguns processos que surgiram e influenciaram a indústria cultural nos últimos setenta anos. Para Rodrigo Duarte o

\footnotetext{
${ }^{5}$ LEBOW, Victor. Price Competition in 1955. In: Journal of Retailing, Spring 1955. Disponível em <http://goo.gl/QaS9am> Acesso em: 24 de Fevereiro de 2014, p.3. (Livre tradução)

${ }^{6}$ Em entrevista dada ao documentário Beyond Citizen Kane de 1993.

${ }^{7}$ COELHO, Teixeira. O que é Indústria Cultural. Brasília: Editora Brasiliense, 1993. 46p. Disponível em <http://goo.gl/oeGzmr> Acesso em: 24 de Fevereiro de 2014, p.7.
}

\begin{tabular}{|c|c|c|c|c|c|}
\hline intuitio & $\begin{array}{c}\text { ISSN } \\
1983-4012\end{array}$ & Porto Alegre & Vol.7 - No.2 & $\begin{array}{c}\text { Novembro } \\
2014\end{array}$ & p.104-121 \\
\hline
\end{tabular}


processo mais significativo seria o da globalização. ${ }^{8}$ Evidentemente nossa intenção aqui não é nos aprofundarmos neste complexo conceito, mas é de apenas estabelecermos alguns links entre a internet e concepção clássica de indústria cultural.

Duarte acredita que a globalização reintroduziu a discussão sobre a indústria cultural, porém de uma forma ainda mais potente, na qual até as fronteiras nacionais e as soberanias estatais da informação foram superadas pela supremacia daquilo que o sociólogo inglês Scott Lash chamou de indústria cultural global.

Com base nisso o sociólogo alemão Ulrich Beck ${ }^{9}$ faz uma análise séria que não chega ser apocalíptica, porém também não é totalmente apologética ao status quo globalizado. De um lado negativo, a globalização teria levado a degeneração da classe operária, a rebaixou ao nível de uma "subclasse". Isto foi possível devido ao avanço tecnológico e da melhora das condições de trabalho que foram resultado da luta desta própria classe. Principalmente nos países desenvolvidos, mas hoje até mesmo nos países pobres em desenvolvimento como o Brasil, a classe operária que se opunha aos ideais burgueses foi aos poucos dando lugar a chamada "nova classe média". Evidentemente esta "nova classe" ainda é formada pelos mais pobres e oprimidos, porém a indústria cultural financiada por governos e por multinacionais doutrinou as massas a não desejarem lutar contra o sistema, mas sim lutar pelo sistema. O desejo de transformação social através do esforço coletivo foi perdendo espaço para o ideal de ascensão social pelo esforço individual. A indústria cultural de fato é grande responsável por isso, afinal viu desde cedo o poder de consumo da nova classe média e com seus produtos pregou a ideia que a luta coletiva seria utópica e por outro lado o esforço individual seria a garantia da prosperidade. Desta forma os capitalistas clássicos que outrora encontravam no operário socialista um limite para sua expansão mundial, no funcionário da nova classe média encontram um interessante aliado. ${ }^{10}$ Por outro lado, a transmissão de guerras ao vivo, bem como a transmissão de catástrofes naturais, por exemplo, são capazes de causar uma comoção gigantesca nas massas e gerar aquilo que Beck chama de solidariedade internacional. Evidentemente todo este processo ainda está ocorrendo diante de nós e a única certeza que já temos é a de sua ambiguidade e contradição nativa que já era verificada desde o início do século XX quando colocávamos lado a lado os textos de Benjamin e Adorno.

A já citada ideologia do status quo observada por Adorno e Horkheimer se tornou tão soberana que alguns estudiosos como Yoshihiro Francis Fukuyama chegaram a proclamar o fim

\footnotetext{
${ }^{8}$ DUARTE, Rodrigo. Teoria Crítica da Indústria Cultural. Belo Horizonte: ed. UFMG, 2003. 218p. Disponível em: <http://goo.gl/cNpNy0> Acesso em: 24 de Fevereiro de 2014, p.147.

9 Cf. BECK, Ulrich. ¿Qué es la globalización? Falacias del globalismo, respuestas a la globalización. Barcelona: Paidós, 1998, 221 p. (Paidós Estado y Sociedad; 58).

${ }^{10}$ DUARTE, Rodrigo. Teoria Crítica da Indústria Cultural. Belo Horizonte: ed. UFMG, 2003. $218 \mathrm{p}$. Disponível em: <http://goo.gl/cNpNy0> Acesso em: 24 de Fevereiro de 2014, p.149.
}

\begin{tabular}{|c|c|l|l|c|c|}
\hline intuitio & $\begin{array}{c}\text { ISSN } \\
1983-4012\end{array}$ & Porto Alegre & Vol.7- $\mathrm{N}^{\mathrm{o}} .2$ & $\begin{array}{c}\text { Novembro } \\
2014\end{array}$ & p.104-121 \\
\hline
\end{tabular}


da história, o fim da ideologia e progresso do processo de globalização. ${ }^{11}$ Porém, esta não foi uma opinião que se consolidou nos últimos anos, mesmo após a queda do Muro de Berlim assistimos uma enxurrada de conflitos, porém o que vimos não foi o surgimento de um novo Hitler, até porque o padrão hoje é o da pseudoindividualização, o que temos são pequenos e poderosos grupos que transcendem barreiras nacionais e que defendem interesses específicos, o exemplo mais claro que podemos observar é a Al-Qaeda, uma organização terrorista que tem como base o fundamentalismo islâmico, mas que é internacional, constituída por células colaborativas e independentes.

Ulrich Beck fala sobre a relativação das fronteiras e isto sem dúvida é uma realidade do mundo globalizado. $\mathrm{Na}$ economia isso fica evidente quando observamos as grandes multinacionais, vemos uma empresa de calçados norte americana que tem todas suas fábricas na Ásia e vende seus produtos na Europa. Na indústria cultural isso não é muito diferente, um filme é produzido por Hollywood por um diretor europeu, gravado por uma empresa japonesa, distribuído por alguma empresa chinesa e chega até as casas de pessoas na África que assistem e acabam por reproduzir padrões de comportamento que não são exatamente Americanos, Europeus, Asiáticos ou Africanos, são padrões globalizados.

O jornalismo se tornou um grande produto da indústria cultural global e a partir do momento que os satélites atropelaram todas as fronteiras nacionais e de classe. A posse da informação alienou-se inclusive dos interesses dos poderes tradicionalmente estabelecidos. Se desde os tempos dos arautos a comunicação sempre respondeu aos interesses dos governantes, num mundo globalizado isto mudou drasticamente. Por mais rígido que possa ser o sistema de concessão midiática de um país, a informação sempre acaba chegando por meio da indústria cultural global, isto se daria devido àquilo que Beck chama de Rede mundial de informação:

\begin{abstract}
Vários exemplos disso são dados por Beck: o primeiro deles refere-se ao discurso do então presidente russo Bóris Iélsin, ao se posicionar contra uma tentativa de retomada do poder pela força, por parte de comunistas. O discurso não foi transmitido pela rádio e pela televisão russa, que eram politicamente controladas pelo Partido Comunista, mas foi ao ar para todo mundo (inclusive para Rússia) através da CNN. Para Beck isto é um exemplo concreto da atual da atual ilimitação do fluxo informacional, o que transcende, em muito a capacidade de coerção de um poder localmente constituído: "Neste momento histórico de decisão política, o significado escandaloso de uma rede global de informação torna-se exemplarmente reconhecido: a soberania da informação de um Estado nacional, enquanto parte da soberania política é posta fora de combate."12
\end{abstract}

Porém isso nem de longe deve ser um motivo de comemoração por nossa parte. Nos

${ }^{11}$ Cf. FUKUYAMA, Francis. The end of history. In: The national interest, 1989. Disponível em: <http://goo.gl/TjqnmK> Acesso em: 24 de Fevereiro de 2014.

12 DUARTE, Rodrigo. Teoria Crítica da Indústria Cultural. Belo Horizonte: ed. UFMG, 2003. $218 \mathrm{p}$. Disponível em: <http://goo.gl/cNpNy0> Acesso em: 24 de Fevereiro de 2014, p.151.

\begin{tabular}{|c|c|l|l|c|c|}
\hline intuitio & $\begin{array}{c}\text { ISSN } \\
1983-4012\end{array}$ & Porto Alegre & Vol.7 $-\mathrm{N}^{\circ} .2$ & $\begin{array}{c}\text { Novembro } \\
2014\end{array}$ & p.104-121 \\
\hline
\end{tabular}


deve ficar claro que o discurso Bóris Iélsin só foi ao ar pois era de interesse da CNN e de seus respectivos anunciantes. Desta forma não é exagero afirmarmos que a indústria cultural global possui um poder manipulatório ainda mais forte e escancarado em relação a sua concepção clássica.

Outra consequência da globalização é a globalização cultural. Ao contrário do que se possa pensar, isto para Ulrich não significa somente a padronização da cultura como previa Adorno desde os anos 1930, trata-se de um processo contraditório, em que de um lado há sim esta estandardização, mas do outro há uma simbiose positiva entre o distante e o próximo. ${ }^{13}$ Boa parte da programação da televisão por assinatura se dedica a mostrar hábitos e culturas distantes, desta forma conhecemos muito mais hoje as culturas distantes e as culturas distantes conhecem muito mais os nossos hábitos e costumes. A indústria cultural global reificou na forma de mercadoria este tipo tradicional de cultura fechada em si mesmo e baseada em operadores tradicionais de identidade como: nacionalidade, raça, classe, etc. Isto poderia nos levar a pensar que este processo acabaria por reforçar as culturas individuais, pois hoje é mais fácil reconhecermos nossas diferenças, porém não é bem assim que acontece, o novo operador identitário oriundo da indústria cultural faz com que no fim das contas todas estas culturas diferentes se tornem apenas subculturas, apenas extensões da ideologia dominante do status quo, algo próximo a uma aldeia global como supunha McLuhan já nos anos 1960, porém não exatamente assim como veremos. Apenas para reforçar a dimensão de padronização da cultura, temos que ter em mente que no início dos anos 2000 pouco mais de uma dúzia de corporações controlavam quase toda oferta de mercadorias culturais no mercado mundial. ${ }^{14}$

Além da globalização que deu poder à indústria cultural lhe transformando em indústria cultural global, Rodrigo Duarte apresenta uma série de mudanças que transformaram radicalmente a realidade da comunicação em relação à crítica de Adorno e Horkheimer. Tais mudanças teriam ocorrido principalmente nas décadas de 1980 e 1990 com a formação dos grandes oligopólios mundiais da comunicação.

O primeiro ponto de todas estas mudanças se deu com a compra da Twentieth CenturyFox pelo player australiano Rupert Murdoch em 1985. Ele não ficou somente com o estúdio de cinema, criou a emissora Fox TV que abalou o mercado televisivo norte americano, pois ditou um novo padrão cinematográfico para a programação televisiva. Introduziu também o conceito de Reality TV explorando dramas e história reais, por fim, Murdoch comprou em 1993 o sistema de canais por satélite Star TV ampliando sua audiência em milhões de pessoas e transmitindo

\footnotetext{
${ }^{13}$ DUARTE, Rodrigo. Teoria Crítica da Indústria Cultural. Belo Horizonte: ed. UFMG, 2003. 218p. Disponível em: <http://goo.gl/cNpNy0> Acesso em: 24 de Fevereiro de 2014, p.152.

${ }^{14}$ DUARTE, Rodrigo. Teoria Crítica da Indústria Cultural. Belo Horizonte: ed. UFMG, 2003. $218 \mathrm{p}$. Disponível em: <http://goo.gl/cNpNy0> Acesso em: 24 de Fevereiro de 2014, p.159.
}

\begin{tabular}{|c|c|l|l|c|c|}
\hline intuitio & $\begin{array}{c}\text { ISSN } \\
1983-4012\end{array}$ & Porto Alegre & Vol.7 $-\mathrm{N}^{\mathrm{o}} .2$ & $\begin{array}{c}\text { Novembro } \\
2014\end{array}$ & p.104-121 \\
\hline
\end{tabular}


sua programação para diversos novos países (novos mercados consumidores). ${ }^{15}$

O segundo ponto é crucial, pois muda muito a situação de dependência da indústria cultural frente a outras indústrias da época de Adorno, neste ponto grandes empresas fabricantes de hardware eletrônicos da comunicação compraram (ou se uniram) às principais corporações midiáticas existentes, além disso, este ponto também significou a fusão de empresas ocidentais e orientais. A Sony em 1988 comprou a gravadora CBS e depois comprou o estúdio cinematográfico Columbia Pictures. O conglomerado Matsushita formado por Panasonic, JVC e Technics comprou em 1990 a MCA/Universal e lançou em 1993 o filme Jurassic Park que além de gerar lucros na casa de absurdos 900\%, introduziu a então revolucionária tecnologia de efeitos de computação gráfica elaborada pela Silicon Graphics. Também a Warner junto com CNN e a Toshiba formaram a partir de 1989 a Time Warner que se tornaria o maior e mais lucrativo conglomerado de mídia. ${ }^{16}$

O terceiro ponto pode ser observado com a criação da MTV por parte do conglomerado Viacom Media Networks em 1981. Trata-se de um canal de programação feita para adolescentes e jovens adultos onde a música é o produto principal através da exibição de vídeo clipes. Com um núcleo de programação baseado em artistas de língua inglesa, sem dúvidas a MTV foi uma das principais responsáveis pela globalização cultural e pela padronização da cultura pop nas décadas de 1980 e 1990 divulgando diversos hits e astros de gravadoras como BMG, Polygram, EMI, Sony Music, Virgin, Geffen e Island. Nesta época o limiar entre o que era e o que não era pop dependia da exibição ou não do produto na MTV. ${ }^{17}$

O quarto ponto era visto apenas como uma possibilidade por Rodrigo Duarte em 2003, porém hoje já é uma realidade não só na televisão por assinatura, como também na televisão aberta. Trata-se da TV Digital:

Isto tende a mudar radicalmente os processos de comercialização das mercadorias culturais, pois, em função da capacidade disponível, os custos de transmissão cairão sensivelmente e, em um futuro talvez não muito distante, os grandes oligopólios de media (que hoje são poucos em todo o mundo) não precisarão mais licenciar seus produtos junto aos canais de televisão do resto do mundo, mas fornecê-los diretamente através de canais de satélites digitais e embolsar, eles próprios o dinheiro da publicidade. Isso ocorre, em parte, através do sistema de satélites digital europeu Astra e dos sistemas similares mundiais como o Sky e DirecTV (a primeira pertence ao grupo do mencionado Rupert Murdoch) ${ }^{18}$

15 DUARTE, Rodrigo. Teoria Crítica da Indústria Cultural. Belo Horizonte: ed. UFMG, 2003. 218p. Disponível em: <http://goo.gl/cNpNy0> Acesso em: 24 de Fevereiro de 2014, p.160-162.

${ }^{16}$ DUARTE, Rodrigo. Teoria Crítica da Indústria Cultural. Belo Horizonte: ed. UFMG, 2003. 218p. Disponível em: <http://goo.gl/cNpNy0> Acesso em: 24 de Fevereiro de 2014, p.162-163.

17 DUARTE, Rodrigo. Teoria Crítica da Indústria Cultural. Belo Horizonte: ed. UFMG, 2003. 218p. Disponível em: <http://goo.gl/cNpNy0> Acesso em: 24 de Fevereiro de 2014, p.163-164.

${ }^{18}$ DUARTE, Rodrigo. Teoria Crítica da Indústria Cultural. Belo Horizonte: ed. UFMG, 2003. $218 \mathrm{p}$. Disponível em: <http://goo.gl/cNpNy0> Acesso em: 24 de Fevereiro de 2014, p.165.

\begin{tabular}{|c|c|l|l|l|l|}
\hline intuitio & $\begin{array}{c}\text { ISSN } \\
1983-4012\end{array}$ & Porto Alegre & Vol.7 $-\mathrm{N}^{\mathrm{o}} .2$ & $\begin{array}{c}\text { Novembro } \\
2014\end{array}$ & p.104-121 \\
\hline
\end{tabular}


Além da TV digital o quarto ponto também aponta para compra de programação on demand e pay-per-view como consequências da nova tecnologia e o surgimento das Smart tv's (aparelhos de televisão inteligentes que executam funções de computador e telefone) como uma necessidade. Devido a isso as companhias de telefonia também começariam a fazer parte dos novos conglomerados da indústria cultural. Hoje absolutamente todas estes tendências se confirmaram.

O quinto e último ponto da análise de Duarte diz respeito à entrada dos PC's e da internet no ramo da comunicação de massa. Muito antes dos aparelhos televisores incorporarem funções de computadores, foram os computadores que incorporaram funções dos televisores. No início dos anos 1990 Apple e Microsoft trouxeram sistemas operacionais com interfaces muito mais intuitivas e dinâmicas nos quais qualquer um poderia operar. Não demorou muito para fabricantes de hardware desenvolverem os famosos kit multimídia e antes do fim da década de 1990 além de todos os recursos dos novos Macintosh e Windows, os PC's também reproduziam vídeos, músicas, jogos, tocavam e gravam CD’s e alguns computadores mais sofisticados eram capazes de receber sinal de rádio e televisão, permitindo aos usuários até gravarem digitalmente a programação através dos formatos MP3 e AVI.

Assim sendo, mesmo se tratando de um diagnóstico realizado na década de 1940 a crítica de Theodor Adorno e Max Horkheimer à indústria cultural continua válida e é até mesmo "atual", seja no escopo econômico, ideológico ou estético. O único cuidado que precisamos ter ao contemporizar a Dialética do Esclarecimento é que hoje temos uma indústria cultural global que é muito mais poderosa e independente do que aquela que os filósofos da Escola de Frankfurt conheceram. Como vimos neste subcapítulo, tornou-se muito mais independente frente aos governos e frente a outros setores da economia, por isso mesmo se tornou muito mais poderosa frente ao seu público, que somos todos nós.

Por outro lado, a análise de Rodrigo Duarte erra muito ao analisar as tendências do futuro da internet como meio de comunicação. $O$ pensador brasileiro via na popularização do uso do e-mail e dos navegadores World Wide Web apenas a replicação de toda lógica já citada neste trabalho. $\mathrm{O}$ autor chega a citar a fusão do provedor de conteúdo AOL com conglomerado Time Warner como uma tendência para o futuro próximo, na verdade já em 2004 Time Warner percebeu o tremendo erro que significou esta negociação. O que Duarte, bem como a maioria dos analistas da época, não podia prever era a verdadeira revolução que estava para acontecer na internet, um fenômeno que realmente rompeu com paradigmas e estabeleceu novos e até então inesperados padrões para a comunicação de massa, justamente sobre isso dissertaremos no próximo item destes trabalho.

\begin{tabular}{|c|c|l|l|l|l|}
\hline intuitio & $\begin{array}{c}\text { ISSN } \\
1983-4012\end{array}$ & Porto Alegre & Vol.7- $\mathrm{N}^{\circ} .2$ & $\begin{array}{c}\text { Novembro } \\
2014\end{array}$ & p.104-121 \\
\hline
\end{tabular}




\title{
3 Internet
}

Quando falo em internet não podemos aceitar e incluir toda rede mundial de computadores como "uma coisa só", precisamos ter em mente que a internet são "múltiplas internets", que a pluralidade e a diversidade são suas marcas e que tentar entendê-la como "uma coisa só" é um verdadeiro insulto à sua natureza. Por muito tempo se vinculou a imagem do internauta à figura de um navegador que desbrava o oceano virtual em busca de novos mundos, mas esta analogia não é muito adequada, pois a superfície do oceano é um lugar vazio e melancólico, onde sem deparar-se com nada nosso olhar se perde e avistamos apenas uma imaginária linha do horizonte há muitos quilômetros de distância, evidentemente esta não é a imagem que melhor representa a internet hoje. Para Michael K. Bergman no artigo The Deep Web: Surfacing Hidden Value a imagem mais adequada para internet seria a de um oceano profundo e o internauta um pescador em sua embarcação passando uma rede de arrasto:

\begin{abstract}
Pesquisar na Internet hoje pode ser comparado ao ato de jogar uma rede de arrasto através da superfície do oceano. Embora uma grande quantidade de peixes possa ser pescada na rede, ainda há uma riqueza de informações (peixes) que vivem em águas profundas e, portanto, são inacessíveis. A razão é simples: a maioria das informações da Web está submersa em locais bem no final das redes geradas dinamicamente e por isso motores de busca padrão nunca irão encontrá-las. ${ }^{19}$
\end{abstract}

Como veremos, segundo a pesquisa de Mike Bergman a maior parte da informação online não está na superfície, mas sim nas profundezas, a partir disso surge analogia entre os dados da internet e um iceberg. Vejamos então o internauta como um náufrago que após colidir sua embarcação contra este iceberg precisa se agarrar ao gigante de gelo para sobreviver, sobrevivendo precisará encontrar alguma forma de chamar a atenção e ser visto por outras embarcações que possam passar por ali. Seguindo esta analogia, para muitos analistas, assim como um iceberg a internet tem um corpo largo que está em contato com a superfície do mar, um cume reluzente e um uma grande parte submersa e inacessível para quem não mergulhar.

A parte submersa é para Bergman a Deep Web, nela está todo conteúdo que não foi indexado, que por isso mesmo não pode ser acessado por qualquer internauta, nem pode ser localizado por mecanismos de busca como o Google que trabalham apenas com sites indexados ou linkados por outros sites indexados. Em seu mencionado artigo Mike estima que a Deep Web represente cerca de $70 \%$ à $75 \%$ de toda internet, isso significa milhares de sites e milhões de megabits de informação. Tanta informação velada se dá por vários motivos. A grande maioria são bancos de dados que servem de base para o funcionamento de toda rede e por isso mesmo não devem ser acessados, mas existem informações sigilosas, base de dados de governos,

19 BERGMAN, Michael K. White Paper: The Deep Web: Surfacing Hidden Value. Disponível em: <http://goo.gl/MBcsVD> Acesso em: 18 de Fevereiro de 2014. (Livre tradução)

\begin{tabular}{|l|c|c|c|c|c|}
\hline intuitio & $\begin{array}{c}\text { ISSN } \\
1983-4012\end{array}$ & Porto Alegre & Vol.7 $-\mathrm{N}^{\mathrm{o} .2}$ & $\begin{array}{c}\text { Novembro } \\
2014\end{array}$ & p.104-121 \\
\hline
\end{tabular}


intranets de empresas, sites que não foram indexados pela ignorância dos programadores e até mesmo fóruns e páginas que por lidarem com atividades ilegais e não querem ser localizados.

Com isto em mente, a BrightPlanet quantificou o tamanho e a relevância da Deep Web em um estudo com base em dados coletados [...] Nossas descobertas chave incluem:

- Informação pública na Deep Web é atualmente 400 a 550 vezes maior do que aquilo que o mundo comumente define como World Wide Web.

- A Deep Web contém 7.500 terabytes de informação em comparação com 19 terabytes de informação na Surface Web.

- A Deep Web contém cerca de 550 bilhões de documentos individuais em comparação com o 1 bilhão da Surface Web. [...]

- A Deep Web é categoria que mais recebe novas informações na Internet.[...]

- Mais da metade do conteúdo da Deep Web reside em bancos de dados de tópicos específicos. ${ }^{20}$

A parte mais larga do iceberg que está em contado com a superfície é a Web 1.0 ou Surface Web, dotada de seus grandes portais que divulgam notícias, informação e entretenimento. No Brasil temos referências nestes meio como o Uol, Terra, Ig, Bol, Gl, R7, etc. Nesta web estão localizados todos sites institucionais, páginas do governo, bancos, lojas, ONGs, pornografia e até sites de divulgação pessoal. Esta parte de internet foi sem dúvidas a mais importante pela consolidação deste meio de comunicação na década de 1990.

O cume reluzente é a Web 2.0 é lá que fixamos nossa bandeira improvisada e clamamos por atenção. Tecnicamente ela faz parte da Surface Web, por isso mesmo muitos especialistas como Timothy John Berners-Lee consideram tal nomenclatura dada por Tim O'Reilly apenas uma jogada marketing. Ela é formada por todas as páginas que possuem estruturas colaborativas de criação e compartilhamento de conteúdo. Habitam este cume as redes sociais, a blogosfera, fóruns públicos, as Wikis, redes de compartilhamento de vídeos, etc. É aqui que popularizou-se o uso na internet a partir da década de 2000 e é onde encontra-se os gigantes do setor como o Google, Facebook, Yahoo, Wikipédia, You Tube, Blogger, Mercado Livre, eBay, MSN, Twitter, etc. O sucesso da Web 2.0 é tão grande que é difícil encontrar alguma página da web tradicional que não incorpore os elementos da Web 2.0 - geralmente botões para compartilhamento e espaço para comentários no fim da página.

Referente à questão dos meios de comunicação e da luta contra a alienação e reificação evidentemente seria interessante nos aprofundarmos no estudo da Deep Web, principalmente frente à comunicação realizada entre hackers e também sobre a resistência popular em países onde as redes sociais são proibidas, porém este é um campo demasiadamente técnico e complexo para ser explorado por um estudo de filosofia como este que aqui vos faço, julgo que seria necessário uma pesquisa interdisciplinar um pouco mais longa que envolvesse especialistas em filosofia, sociologia, comunicação social e informática. Já a Web 1.0

${ }^{20}$ BERGMAN, Michael K. White Paper: The Deep Web: Surfacing Hidden Value. Disponível em: <http://goo.gl/MBcsVD> Acesso em: 18 de Fevereiro de 2014. (Livre tradução)

\begin{tabular}{|c|c|l|l|c|c|}
\hline intuitio & $\begin{array}{c}\text { ISSN } \\
1983-4012\end{array}$ & Porto Alegre & Vol.7- $\mathrm{N}^{\mathrm{o}} .2$ & $\begin{array}{c}\text { Novembro } \\
2014\end{array}$ & p.104-121 \\
\hline
\end{tabular}


poderíamos dizer que faz parte do velho paradigma da indústria cultural, pelo menos no que se refere a centralização e transmissão de informação pelas mãos de grandes empresas do ramo, também pelo já citado gatekeeping e pelo feedback reificado e indireto. Assim sendo, quando falo em internet como um novo paradigma neste trabalho estou referindo-me à Web 2.0 e sua estrutura colaborativa, pois é ai onde sujeito encontra um nível de liberdade que parecia a muito estar perdido, onde cada vez mais se fecham os lugares para velha a tirania da comunicação feita de poucos para muitos, onde o padrão identitário se faz cada vez menos significativo e a democracia consolida-se nas novas praças públicas virtuais. Mas, como veremos até o fim desta obra, não tudo são flores neste novo mundo, precisamos ter um olhar crítico para não fazermos deste mais um temível meio de alienação e reprodução ideológica da realidade vigente.

O conceito de "Web 2.0" teria começado com um brainstorming entre a O'Reilly e a MediaLive International. Neste encontro Dale Doughherty pontuou que a internet estava tomando uma posição central nos meios de comunicação, que milhões de novos sites estavam surgindo e que somente os melhores e mais dinâmicos sobreviveriam, ao contrário dos mais pessimistas que diziam se tratar de uma crise na qual existiam muitos sites e uma enxurrada de publicidade desconexa e irritante, Tim O'Reilly propôs a ideia de que a internet estaria evoluindo, ou mesmo se revolucionando, por isso seria adequado falarmos que experimentávamos uma nova Web, a Web 2.0. Em pouco mais de um ano o termo já possuía mais de 9,5 milhões de citações no Google e muitas discussões e divergências sobre tal conceito começaram a surgir, pensando nisso O'Relly escreve em 2005 o artigo What Is Web 2.0 buscando dar alguns esclarecimentos. ${ }^{21}$

A principal crítica feita ao conceito de Web 2.0 se dá devido ao fato de que os protocolos de comunicação e os servidores de armazenamento nunca mudaram, assim sendo não se trata de uma nova tecnologia, o que seria então? Por que chamá-la de 2.0? O’Relly se defende afirmado que realmente não é uma nova tecnologia, mas sim uma nova maneira de se relacionar com a velha tecnologia. Seriam Web 2.0 sites e empresas que utilizam a internet como plataforma e que possuem um padrão de design que transforma-o em um ambiente colaborativo onde as informações e mensagens só são completas a partir da inteligência coletiva do respectivo público. Visto que isso não era suficiente para esclarecer porque alguns sites seriam 1.0 e outros 2.0 O'Relly parte para uma análise de casos de sucesso na velha web em relação a casos de sucesso na nova. ${ }^{22}$

\footnotetext{
${ }^{21}$ O'REILLY, Tim. O que é Web 2.0: Padrões de design e modelos de negócios para a nova geração de software. 2005. Disponível em: <http://goo.gl/a4Yjto> Acesso em: Acesso em: 24 de Fevereiro de 2014, p.1.

${ }^{22}$ O'REILLY, Tim. $O$ que é Web 2.0: Padrões de design e modelos de negócios para a nova geração de software. 2005. Disponível em: <http://goo.gl/a4Yjto> Acesso em: Acesso em: 24 de Fevereiro de 2014, p.2.
}

\begin{tabular}{|c|c|l|l|l|l|}
\hline intuitio & $\begin{array}{c}\text { ISSN } \\
1983-4012\end{array}$ & Porto Alegre & Vol.7- $\mathrm{N}^{\mathrm{o} .2}$ & $\begin{array}{c}\text { Novembro } \\
2014\end{array}$ & p.104-121 \\
\hline
\end{tabular}


Figura 1 - Esquema e possibilidades de websites

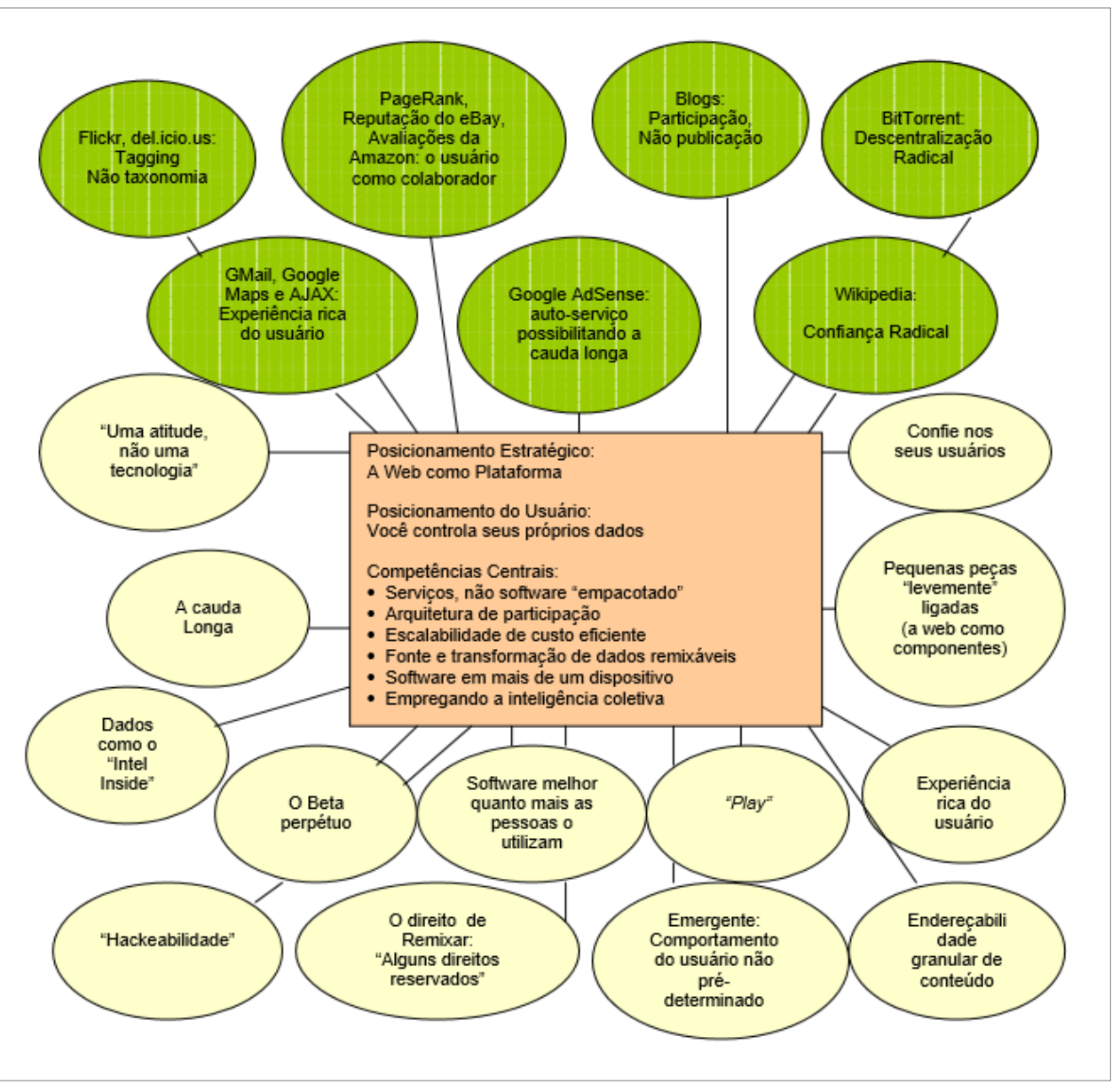

2.0 .

Fonte: O'REILLY (2005, p.3)

Nota: Na figura vemos que o conceito de Web 2.0 não é rígido, porém possui um centro gravitacional comum que inclui algumas características básicas. Podemos ter os mais variados tipos websites 2.0 como demostrado nas esferas verdes e as esferas amarelas mostram características facultativas e interessantes para de Web 2.0.

Antes do Google o Netscape definia o que era tratar "a web como plataforma", porém fazia isso seguindo o velho paradigma da indústria de software, seu carro-chefe era o navegador: um aplicativo que necessitava ser baixado e instalado e funcionava somente para desktop. Para O'Relly a empresa responsável pelo Netscape buscava dominar o mercado de navegadores para ter também o controle também dos servidores e assim vender serviços únicos e caros aos seus clientes. Ela queira ter o tipo de poder de mercado que a Microsoft desfrutava no mercado de $O . S$.

Por outro lado, a empresa Google, embora hoje até possua o O.S. Android e o navegador Chrome, sempre foi uma empresa de serviços nativamente web, poderíamos dizer que ela só criou este O.S. e o seu navegador com intuito de disponibilizar para usuários e programadores softwares de código aberto capazes de proporcionar a experiência online desejada pela mesma. Para O'Relly a Google nunca apresenta velhas armadilhas como

\begin{tabular}{|c|c|l|l|l|l|}
\hline intuitio & $\begin{array}{c}\text { ISSN } \\
1983-4012\end{array}$ & Porto Alegre & Vol.7- $\mathrm{N}^{\circ} .2$ & $\begin{array}{c}\text { Novembro } \\
2014\end{array}$ & p.104-121 \\
\hline
\end{tabular}


obsolescência programada e perceptiva em seus serviços online que seguem a lógica do beta continuo sempre recebendo novas e diárias atualizações baseadas no feedback direto e indireto de seus usuários, mesmo seu O.S. e seu navegador funcionam desta maneira. Os serviços da Google por rodarem em plataforma online podem ser acessados de qualquer sistema e de qualquer lugar, se pode até salvar arquivos no Google Drive e rodá-los diretamente no Google Docs sem a necessidade de se instalar softwares específicos para isso. Especulações sobre um possível Google O.S. nos fazem pensar em um sistema rodando completamente online, com uma área de trabalho semelhante a time line do Google+ e sendo executável de qualquer gadget, até mesmo em algo como o ambicioso e desajeitado projeto Google Glass, no qual o usuário pode acessar a internet a partir de um óculos da empresa. Voltando um pouco ao texto de Tim O'Reilly:

\begin{abstract}
O serviço da Google não é um servidor - embora ele seja prestado através de uma maciça coleção de servidores de Internet -, nem um navegador - embora seja experimentado pelo usuário dentro do navegador. Nem o serviço de busca que é o seu carro-chefe sequer hospeda o conteúdo que ele permite o cliente encontrar. Muito parecido com um telefonema, que acontece não apenas nos aparelhos em cada extremo da ligação mas na rede entre eles, a Google acontece no espaço entre navegador e ferramenta de busca, e o servidor de conteúdo de destino, como um possibilitador ou intermediário entre o(a) usuário(a) e a sua experiência online. ${ }^{23}$
\end{abstract}

Desta forma é correto afirmar que tanto Netscape quanto Google tratam a internet como plataforma, porém enquanto a Netscape seguia as mesas lógicas de empresas de software dos anos 1980 e 1990 como a Lotus, Microsoft, Apple e Oracle; a Google criou novas lógicas e paradigmas rapidamente adotados por outras empresas como eBay, Facebook, Wikipédia e Bit Torrent. Por isso poderíamos enquadrar a Netscape e suas práticas como Web 1.0 e a Google e sua lógica como Web 2.0.

A Bit Torrent e seu homônimo programa gerenciador de downloads tecnicamente nem trabalha com serviço web, pois sua tecnologia é baseada em uma arquitetura de conexão diferenciada. E é justamente por tal arquitetura que Tim O'Reilly acha interessante salientar sua importância no cenário Web 2.0. Na arquitetura P2P utilizada pelo Bit Torrent cada computador conectado e realizando um download funciona como um servidor. Enquanto um usuário baixa um arquivo com o Bit Torrent ele envia fragmentos já descarregados deste arquivo para outros usuários que estejam descarregando o download simultaneamente. Quanto mais popular for o arquivo mais rápido fica o download.

A BitTorrent, portanto, demonstra um princípio chave da Web 2.0: o serviço fica automaticamente melhor quanto mais forem os usuários que o utilizam.

\footnotetext{
${ }^{23}$ O'REILLY, Tim. O que é Web 2.0: Padrões de design e modelos de negócios para a nova geração de software. 2005. Disponível em: <http://goo.gl/a4Yjto> Acesso em: Acesso em: 24 de Fevereiro de 2014, p.6.
}

\begin{tabular}{|c|c|c|c|c|c|}
\hline intuitio & $\begin{array}{c}\text { ISSN } \\
1983-4012\end{array}$ & Porto Alegre & Vol.7 - No.2 & $\begin{array}{c}\text { Novembro } \\
2014\end{array}$ & p.104-121 \\
\hline
\end{tabular}


Enquanto a Akamai precisa adicionar servidores para melhorar o serviço, cada consumidor da BitTorrent traz os seus próprios recursos para o grupo. Existe uma "arquitetura de participação" implícita, uma ética de cooperação embutida pela qual o serviço atua, primariamente, como um intermediário inteligente que conecta as pontas entre si e combina o poder dos próprios usuários. $^{24}$

Mesmo sem usar o P2P ou a forma tão radical do Bit Torrent onde o desempenho técnico da conexão depende do número de usuários online, todos outros serviços de Web 2.0 assumem uma posição de descentralização da internet. Enquanto os velhos provedores como o Terra, Uol, Ig e Aol funcionavam exatamente como emissoras de televisão arrogando expressões como: "o melhor conteúdo" e "conteúdo exclusivo de qualidade"; as redes sociais, wikis e sites de compartilhamento como Facebook, Wikipédia e You Tube não se responsabilizam pela publicação de nenhum conteúdo, passam toda esta responsabilidade para seus usuários. Desta forma é impossível imaginar Facebook, Wikipédia e You Tube sem seus usuários e redes, pois sem eles de fato não são nada. As redes sociais, a blogosfera, wikis e sites de compartilhamento são fenômenos nascidos na Web 2.0 e que tiram proveito daquilo que O'Reilly chama de inteligência coletiva ou sabedoria das massas. ${ }^{25} \mathrm{O}$ artigo What Is Web 2.0 termina listando oito itens que pautam os padrões de design Web 2.0, são eles: 1. A cauda longa - o projeto deve contemplar não somente os grandes sites e empresas do centro da internet como também os sites pequenos e os usuários comuns que estão na cauda, o autosserviço deve ser incentivado; 2. Dados são o próximo "Intel Inside" - sites 2.0 devem tentar manter uma única fonte de dados; 3. Usuários agregam valor - a chave de sucesso é a utilização dos usuários, por isso a arquitetura deve ser colaborativa; 4. Efeitos de rede como padrão - como poucos postarão conteúdo, crie padrões para agregar dados de usuário como efeito colateral ao uso do serviço (botão "like" do Facebook, por exemplo); 5. Alguns direitos reservados - projete para "hackeabilidade" e "remixabilidade", proteja os direitos apenas da parte central do conteúdo; 6. $O$ beta perpétuo - engaje os seus usuários como avaliadores em tempo real e disponibilize constantes atualizações; 7. Coopere, não controle - ofereça interfaces para serviços web e sindicalização de conteúdo e reutilize os serviços de dados de outros; 8. Software para mais de um único dispositivo - quanto mais plataformas melhor, $p c$, smartphones, tablets e videogames são só o início. ${ }^{26}$

\footnotetext{
${ }^{24}$ O'REILLY, Tim. O que é Web 2.0: Padrões de design e modelos de negócios para a nova geração de software. 2005. Disponível em: <http://goo.gl/a4Yjto> Acesso em: Acesso em: 24 de Fevereiro de 2014, p.8.

${ }^{25}$ O'REILLY, Tim. O que é Web 2.0: Padrões de design e modelos de negócios para a nova geração de software. 2005. Disponível em: <http://goo.gl/a4Yjto> Acesso em: Acesso em: 24 de Fevereiro de 2014, p.9-12.

${ }^{26}$ O'REILLY, Tim. O que é Web 2.0: Padrões de design e modelos de negócios para a nova geração de software. 2005. Disponível em: <http://goo.gl/a4Yjto> Acesso em: Acesso em: 24 de Fevereiro de 2014, p.27-29.
}

\begin{tabular}{|c|c|l|l|l|l|}
\hline intuitio & $\begin{array}{c}\text { ISSN } \\
1983-4012\end{array}$ & Porto Alegre & Vol.7 $-\mathrm{N}^{\mathrm{o}} .2$ & $\begin{array}{c}\text { Novembro } \\
2014\end{array}$ & p.104-121 \\
\hline
\end{tabular}


Existe ainda o conceito de Web 3.0, porém ao contrário do conceito de Web 2.0 que surgiu para explicar uma nova porém já existente situação da web, este conceito foi criado por John Markoff para explicar um novo padrão de comunicação que segundo ele pode surgir nos próximos cinco ou dez anos. Este novo padrão seria menos pautado sobre a participação dos usuários e mais nas estruturas dos sites, na inteligência artificial e nos mecanismo de busca. Hoje a web é formada de uma imensidão de arquivos online, com a Web 3.0 teremos um World Wide Database (base de dados mundial) que possibilitará que as pesquisas fiquem mais rápidas, semânticas e inteligentes. Evidentemente necessitaríamos um nível de Indiligência Artificial que ainda não existe, onde possamos nos comunicar de forma natural com os computadores (não somente com linguagem de programação). Se hoje os computadores, softwares e a Web 2.0 potencializam nossa comunicação e nossos pensamentos, quando chegarmos ao nível da Web 3.0 os computadores pensarão conosco. Navegar pela Web 3.0 será algo muito mais simples e intuitivo, a integração entre o ser humano e o computador será muito maior, porém hoje tudo isso não passa de um sonho ou no máximo projetos daqueles que resolveram acreditar em tal Web do futuro.

Pesquisadores e empreendedores dizem que apesar de ser improvável que haja sistemas completos de inteligência artificial tão cedo, se é que algum dia existirão, a Internet atualmente está produzindo uma cascata crescente de sistemas baseados em inteligência útil a partir de esforços comerciais para estruturar e explorar a Internet. Áreas específicas como sites de viagens e críticas de restaurantes e produtos são candidatas óbvias para construção de tais sistemas, que prenunciariam a chegada da Web 3.0. ${ }^{27}$

\section{Considerações finais}

Passados mais de setenta anos da crítica de Adorno e Horkheimer sobre a indústria cultural, a mesma continua válida e é até mesmo "atual", seja no escopo econômico, ideológico ou estético. O único cuidado que precisamos ter ao contemporizá-la é que hoje devido ao processo de globalização temos uma indústria cultural global que é muito mais poderosa e independente do que aquela que os filósofos da Escola de Frankfurt conheceram.

A internet se popularizou na segunda metade da década de 1990 e em menos de dez anos evoluiria tanto que traria ao campo das comunicações de massa uma revolução tão grande que basicamente nenhum analista poderia prever e que até hoje alguns relutam em aceitar. Esta revolução é aquilo que Tim O’Reilly chamou de Web 2.0. Tal web é formada por todas as páginas que possuem estruturas colaborativas de criação e compartilhamento de conteúdo, como: redes sociais, a blogosfera, fóruns públicos, as Wikis, redes de compartilhamento de

\footnotetext{
${ }^{27}$ MARKOFF, John. Empreendedores vêem uma Internet 3.0 guiada pelo senso comum. 2006. Disponível em: <http://goo.gl/WLA9uN> Acesso em: 18 de Fevereiro de 2014.
}

\begin{tabular}{|c|c|c|c|c|c|}
\hline intuitio & $\begin{array}{c}\text { ISSN } \\
1983-4012\end{array}$ & Porto Alegre & Vol.7 - No.2 & $\begin{array}{c}\text { Novembro } \\
2014\end{array}$ & p.104-121 \\
\hline
\end{tabular}


vídeos, etc. Em pouco tempo nomes completamente alheios aos oligopólios culturais como: Google, Fecebook, Yahoo, Wikipédia, YouTube, Blogger, Mercado Livre, eBay, MSN, Twitter, etc., assumiram posição central neste novo processo de comunicação. A Web 2.0 dá um nó na divisão lógica entre meios de comunicação de massa individuais-interpessoais e meios de comunicação de massa, como não há centralização, a fonte dos conteúdos vem dos próprios usuários que postam e compartilham todas informações, desta forma absolutamente não se trata de uma "comunicação para a massa". Por isso mesmo julgo que não devemos chamar a comunicação realizada na Web 2.0 de "comunicação de massa", proponho adaptarmos o termo "Comunicação em rede" oriundo da informática para este novo cenário, vejamos isto com mais atenção em pesquisas futuras. O fato que precisamos agora considerar e buscar entender é como este novo modelo de comunicação já está abalando a estrutura política neste início de século. Pois não somente uma revolução na própria internet, a Web 2.0 tem revolucionado a maneira dos seres humanos se comunicarem, relacionarem-se e até mesmo o jeito de se fazer protestos políticos. $^{28}$

\section{Referências}

ADORNO, Theodor W.; HORKHEIMER, Max. Dialética do Esclarecimento. 1947. Disponível em: <http://goo.gl/YDDT7S> Acesso em: 23 de Fevereiro de 2014.

ADORNO, Theodor W. Música Popular e Protesto[Entrevista]. Disponível em: 〈http://goo.gl/CdEiPU> Acesso em: 19 de Fevereiro de 2014.

Sobre música popular. In: COHN, Gabriel. Org. Coleção Grandes Cientistas Sociais. São Paulo: Ática, 1986. 115-146p. Disponível em: 〈http://goo.gl/uQ3LiN> Acesso em: 24 de Fevereiro de 2014.

O Fetichismo na Música e a Regressão da Audição. In: Textos escolhidos. São Paulo: Editora Nova Cultural, 1996. 65-108p. Disponível em: 〈http://goo.gl/rUcpGA〉 Acesso em: 24 de Fevereiro de 2014.

AGAMBEN, Giorgio. Profanações. Trad. e apres. Selvino José Assmann. São Paulo: Boitempo, 2007, 96p.

BECK, Ulrich. ¿Qué es la globalización? Falacias del globalismo, respuestas a la globalización. Barcelona: Paidós, 1998, 221 p. (Paidós Estado y Sociedad; 58)

BENJAMIN, Walter. A obra de arte na era da reprodutibilidade técnica. Primeira Versão, 1955. Disponível em: <http://goo.gl/TRTTq0> Acesso em: Acesso em: 24 de Fevereiro de 2014.

O Narrador: observações sobre a obra de Nikolai Leskow. In: Benjamin, Horkeimer, Adorno e

Habermas - Textos escolhidos. São Paulo: Abril, 1975. Coleção Os pensadores. P.63-81. Disponível em: <http://goo.gl/VG4iKA> Acesso em: 24 de Fevereiro de 2014.

BERGMAN, Michael K. White Paper: The Deep Web: Surfacing Hidden Value. Disponível em: <http://goo.gl/MBcsVD> Acesso em: 18 de Fevereiro de 2014.

COELHO, Teixeira. O que é Indústria Cultural. Brasília: Editora Brasiliense, 1993. 46p. Disponível em <http://goo.gl/oeGzmr> Acesso em: 24 de Fevereiro de 2014.

DUARTE, Rodrigo. Teoria Crítica da Indústria Cultural. Belo Horizonte: ed. UFMG, 2003. 218p. Disponível em: 〈http://goo.gl/cNpNy0> Acesso em: 24 de Fevereiro de 2014.

FUKUYAMA, Francis. The end of history. In: The national interest, 1989. Disponível em: <http://goo.gl/TjqnmK> Acesso em: 24 de Fevereiro de 2014.

GOULART, Fabio. Sob a Brisa Fantasmagórica de uma Nova Auschwitz. Disponível em:

${ }^{28}$ Para mais informações sobre isso leia o artigo Sincronia Cosmopolita Febril. Disponível em Disponível em: <http://goo.gl/ZgDBuz $\geq$ Acesso em: 24 de Fevereiro de 2014.

\begin{tabular}{|c|c|l|l|c|c|}
\hline intuitio & $\begin{array}{c}\text { ISSN } \\
1983-4012\end{array}$ & Porto Alegre & Vol.7- $\mathrm{N}^{\mathrm{o} .2}$ & $\begin{array}{c}\text { Novembro } \\
2014\end{array}$ & p.104-121 \\
\hline
\end{tabular}


<http://goo.gl/K7KAx0> Acesso em: 03 de Junho de 2013.

. Sincronia Cosmopolita Febril Revista. In: Revista Opinião Filosófica, Porto Alegre, v. 03; $\mathrm{n}^{\circ}$. 01, 2012, p.202-213. Disponível em: <http://goo.gl/ZgDBuz> Acesso em: 24 de Fevereiro de 2014.

HARTOG, Simon. Beyond Citizen Kane (Muito Além do Cidadão Kane). In: You Tube (1h 33min e 02seg), 1993. Disponível em: <http://goo.gl/YIxfJD> Acesso em: 24 de Fevereiro de 2014.

LEBOW, Victor. Price Competition in 1955. In: Journal of Retailing, Spring 1955. Disponível em <http://goo.gl/QaS9am> Acesso em: 24 de Fevereiro de 2014.

MARKOFF, John. Empreendedores vêem uma Internet 3.0 guiada pelo senso comum. 2006. Disponível em: <http://goo.gl/WLA9uN> Acesso em: 18 de Fevereiro de 2014.

O'REILLY, Tim. O que é Web 2.0: Padrões de design e modelos de negócios para a nova geração de software. 2005. Disponível em: <http://goo.gl/a4Yjto> Acesso em: Acesso em: 24 de Fevereiro de 2014.

Recebido em: 25/05/2014

Aprovado para publicação em: 03/09/2014 